\title{
Non-intubated video-assisted thoracoscopic bullectomy by paravetebral block and sedation
}

\author{
Paravertebral blok ve sedasyon eşliğinde entübasyonsuz \\ video yardımlı torakoskopik büllektomi
}

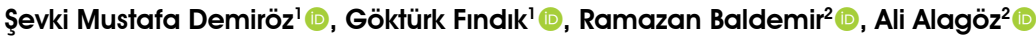 \\ 'Department of Thoracic Surgery, University of Health Sciences, Ankara Atatürk Chest Diseases and Thoracic Surgery \\ Training and Research Hospital, Ankara, Turkey \\ ${ }^{2}$ Department of Anesthesiology and Reanimation, University of Health Sciences, Ankara Atatürk Chest Diseases and Thoracic Surgery \\ Training and Research Hospital, Ankara, Turkey
}

Video-assisted thoracoscopic surgery (VATS) is the standard treatment for bullous lung disease. Non-intubated VATS (NIVATS) prevents patient from the potential risks of general anesthesia and intubation ${ }^{[1]}$ It is a safe procedure with similar reliability compared to VATS performed under general anesthesia. ${ }^{[2]}$ Also, NIVATS can be used in patients with severe pulmonary comorbidity to prevent postoperative ventilator dependency. Pregnant patients who are at risk for anesthetic and surgical interventions may also benefit from NIVATS. ${ }^{[3]}$

In cases where epidural anesthesia is contraindicated, a paravertebral block (PVB) and intercostal blocks are some of the other alternatives. Davies et al. ${ }^{[4]}$ showed that PVB yielded similar postoperative pain control to epidural anesthesia. The PVB makes possible to perform a variety of NIVATS procedures with local infiltration and mild sedation. ${ }^{[3,4]}$ Choices for airway management during NIVATS include face mask, laryngeal mask airway, high-flow nasal cannula, and oropharyngeal cannula. ${ }^{[5]}$ Although we only used a nasal cannula with $2-4 \mathrm{~L} / \mathrm{min}$ oxygen, no hypoxia or hypercarbia were developed during the procedure.

The depth of sedation may change from mildly sedated but communicable and cooperative to a sedation level of general anesthesia. ${ }^{[5]}$ In our patient, a mild level of sedation was maintained by intermittent midazolam and ketamine administration. The cough reflex may be challenging for the surgical intervention. Some authors have suggested either intrathoracic vagus nerve infiltration or preemptive inhalation of nebulized lidocaine $2 \%$ for $30 \mathrm{~min}$ before surgery to overcome this reflex. ${ }^{[5]}$ In our case, we did not block the vagal stimulation and patient coughed at the time of the closure of the stapling device on lung parenchyma; however, it did not affect the surgical intervention. Postoperative analgesics consist of oral analgesics or intravenous analgesics. ${ }^{[5]}$ Our patient received intravenous paracetamol and oral non-steroid anti-inflammatory drugs for pain control.

\section{Technique}

The patient was taken to the operation room in lateral decubitus position. Midazolam $1 \mathrm{mg}$ and fentanyl $25 \mu \mathrm{g}$ intravenous (IV) was used for pre-procedural sedation to prevent from pain during PVB. Paravertebral blockage was made under the guidance of a neural stimulator. Twenty min later, the blockage was confirmed. At the time of initial surgical incision, an additional $1 \mathrm{mg}$ of midazolam and $30 \mathrm{mg}$ of ketamine IV was applied. Another additional $20 \mathrm{mg}$ of ketamine IV was used intraoperative to maintain sedation. The existing chest tube incision was used as the camera port and an additional anterior axillary 3-cm utility incision was made under local anesthesia. Apical bullae were excised by the help

Received: January 19, 2020 Accepted: February 26, 2020 Published online: January 13, 2021

Correspondence: Şevki Mustafa Demiröz, MD. SBÜ Ankara Atatürk Göğüs Hastalıkları ve Göğüs Cerrahisi Eğitim ve Araştırma Hastanesi, Göğüs Cerrahisi Kliniği, 06280 Keçiören, Ankara, Türkiye. Tel: +90532-430 0525 e-mail: demirozsm@gmail.com 


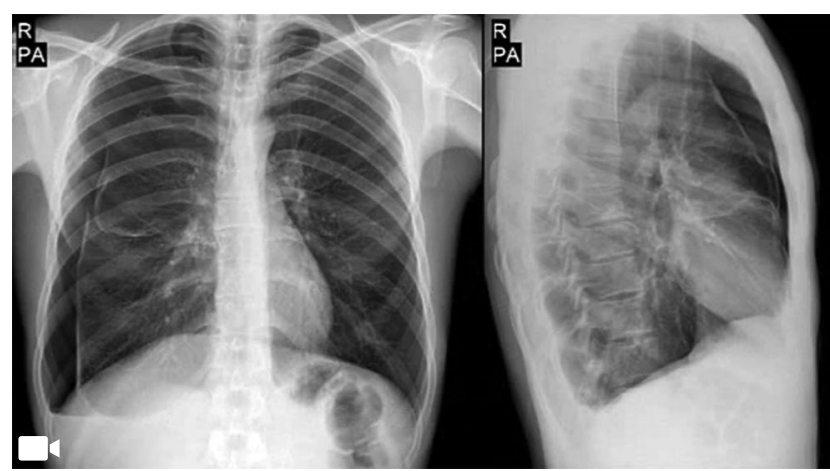

Video 1. Non-intubated video-assisted thoracoscopic bullectomy by paravetebral block and sedation: From pre-procedural preparation to discharge.

of two endoscopic stapling devices (Video 1). After bleeding and air leakage control, the operation was terminated by the insertion of a single chest tube. Total operation time was $12 \mathrm{~min}$. Subsequently, the patient was followed in the recovery room for $1 \mathrm{~h}$. The lung was totally expanded on postoperative chest X-ray without any air leakage.

\section{Comments}

The use of NIVATS minimizes the risks may arise due to the use of intubation and general anesthesia. A survey from the European Society of Thoracic Surgeons (ESTS) demonstrated that NIVATS was started to be used widely by the ESTS members to perform simple VATS procedures. ${ }^{[6]}$ The NIVATS seems to be more feasible for patients with low cardiopulmonary functions to avoid risks of general anesthesia and postoperative mechanical ventilator dependency. ${ }^{[3]}$ Thoracic epidural anesthesia is the most common used analgesic technique during NIVATS. ${ }^{[5]}$ The PVB is a rising choice of selection for not only the cases where epidural anesthesia is contraindicated, but also for a wide range of simple thoracic surgical procedures in selected patients. ${ }^{[3]}$ There are many reports with limited case numbers discussing intraoperative and early postoperative benefits of NIVATS in the literature. However, further studies with larger groups should be conducted to evaluate its long-term results.

\section{Declaration of conflicting interests}

The authors declared no conflicts of interest with respect to the authorship and/or publication of this article.

\section{Funding}

The authors received no financial support for the research and/or authorship of this article.

\section{REFERENCES}

1. Yanık F, Çopuroğlu E, Balta C, Karamustafaoğlu Altemur Y. Awake video-assisted thoracoscopic bullectomy and pleural abrasion. Turk Gogus Kalp Dama 2017;25:137-9.

2. Kocatürk C, Kutluk AC, Usluer O, Onat S, Çınar HU, Yanık $\mathrm{F}$, et al. Comparison of awake and intubated video-assisted thoracoscopic surgery in the diagnosis of pleural diseases: A prospective multicenter randomized trial. Turk Gogus Kalp Damar Cerrahisi Derg 2019;27:550-6.

3. Zheng H, Hu XF, Jiang GN, Ding JA, Zhu YM. Nonintubatedawake anesthesia for uniportal video-assisted thoracic surgery procedures. Thorac Surg Clin 2017;27:399-406.

4. Davies RG, Myles PS, Graham JM. A comparison of the analgesic efficacy and side-effects of paravertebral vs epidural blockade for thoracotomy--a systematic review and meta-analysis of randomized trials. $\mathrm{Br} \mathrm{J}$ Anaesth 2006;96:418-26.

5. Hung WT, Cheng YJ, Chen JS. Video-assisted thoracoscopic surgery lobectomy for lung cancer in nonintubated anesthesia. Thorac Surg Clin 2020;30:73-82.

6. Pompeo E, Sorge R, Akopov A, Congregado M, Grodzki T; ESTS Non-intubated Thoracic Surgery Working Group. Non-intubated thoracic surgery-A survey from the European Society of Thoracic Surgeons. Ann Transl Med 2015;3:37. 